\title{
HUBUNGAN INISIASI MENYUSUI DINI (IMD) DENGAN KELANCARAN PRODUKSI ASI PADA IBU POST PARTUM DI POSYANDU DESA BANGUN SARI BARU TANJUNG MORAWA TAHUN 2021
}

\author{
Nila Hayati ${ }^{1}$, Jojor Patina Rumapea ${ }^{2}$ \\ Universitas Haji Sumatera Utara, Medan, Indonesia \\ Email : nilahayati28@gmail.com,jojor12@gmail.com
}

\begin{abstract}
Abstrak
Kelancaran produksi ASI salah satu penunjang terpenuhinya asupan nutrisi khususnya bagi bayi. Salah satu upaya yang dilakukan oleh ibu post partum untuk kelancaran produksi asi dengan melakukan inisiasi menyusui dini (IMD).Penelitian ini bertujuan untuk mengetahui tentang Hubungan Inisiasi Menyusui Dini (IMD) dengan Kelancaran Produksi Asi Pada Ibu Post Partum di Posyandu Desa Bangun Sari Baru Tanjung Morawa Tahun 2021.Penelitian ini merupakan penelitian descriptive correlation pendekatan Cross sectional. Penelitian ini telah dilaksanakan pada Juli 2021 sampai dengan Agustus 2021. Populasi berjumlah 31 orang. Pengambilan sampel menggunakan total sampling dengan jumlah sampel sebanyak 31 orang. Hasil Penelitian didapat bahwa Inisiasi Menyusui Dini (IMD) di Posyandu Desa Bangun Sari Baru Tanjung Morawa mayoritas tidak melakukan IMD dan Kelancaran Produksi ASI di Posyandu Desa Bangun Sari Baru Tanjung Morawa mayoritas tidak lancar. Berdasarkan hasil uji chisquare didapatkan bahwa inisiasi menyusui dini $(\mathrm{p}=0,018<0,05)$. Saran dalam penelitian ini adalah tenaga kesehatan dapat lebih meningkatkan pengetahuan ibu akan pentingnya melakukan IMD sehingga dapat terpenuhi gizi untuk tumbuh kembang bayi serta kelancaran produksi asi dengan memberikan penyuluhan dan informasi terkait hal tersebut. Sehingga dapat disimpulkan bahwa terdapat Hubungan Inisiasi Menyusui Dini (IMD) dengan Kelancaran Produksi Asi Pada Ibu Post Partum di Posyandu Desa Bangun Sari Baru Tanjung Morawa Tahun 2021.
\end{abstract}

Kata Kunci : : Kelancaran ASI, Post Partum

\section{Abstract}

The smooth production of breast milk is one of the supports for the fulfillment of nutritional intake, especially for infants. One of the efforts made by post partum mothers for smooth breast milk production is by conducting early initiation of breastfeeding (IMD). Morawa Year 2021. This research is a descriptive correlation research with cross sectional approach. This research has been carried out from July 2021 to August 2021. The population is 31 people. Sampling using total sampling with a total sample of 31 people. The results showed that the majority of Early Initiation of Breastfeeding (IMD) at the Posyandu in Bangun Sari Baru Village, Tanjung Morawa did not carry out IMD and the smoothness of breast milk production at the Posyandu in Bangun Sari Baru Village, Tanjung Morawa, the majority was not smooth. Based on the results of the chi-square test, it was found that early breastfeeding initiation $(p=0.018<0.05$ ). The suggestion in this study is that health workers can further increase mother's knowledge of the importance of doing IMD so that nutrition can be fulfilled for baby growth and development and smooth breast milk production by providing counseling and information related to this. So it can be concluded that there is a relationship between Early Breastfeeding Initiation (IMD) with Smooth Breast Milk Production in Post Partum Mothers at the Posyandu in Bangun Sari Baru Village, Tanjung Morawa in 2021.

Keywords : : Smooth breastfeeding, Post Partum 


\section{Tahun 2022 \\ Hal. 37-43}

\section{PENDAHULUAN}

ASI adalah makanan pertama yang alami untuk bayi. ASI menyediakan semua energi dan nutrisi yang dibutuhkan bayi untuk bulan-bulan pertama kehidupan. Menyusui adalah cara yang sangat baik dalam menyediakan makanan ideal bagi pertumbuhan dan perkemabangan bayi yang sehat. Manfaat pemberian ASI eksklusif memberikan manfaat bagi bayi dan juga ibunya, bagi ibu yang sedang menyusui dapat mencegah terjadinya perdarahan postpartum, anemia, dan karsinoma mammae. Penelitian lain menunjukkan bahwa manfaat ASI eksklusif bagi ibu dapat menunda kehamilan dan mengecilkan rahim. Besarnya manfaat dari pemberian ASI ini mendorong pemerintah di seluruh dunia agar mendukung praktik pemberian ASI eksklusif (Haryono, 2014).

Dalam rangka menurunkan angka kesakitan dan kematian bayi, UNICEF dan WHO merekomendasikan sebaiknya bayi hanya disusui air susu ibu (ASI) selama paling sedikit 6 bulan dan pemberian ASI dilanjutkan sampai bayi berumur dua tahun. Agar ibu dapat mempertahankan ASI eksklusif selama 6 bulan, WHO merekomendasikan agar melakukan inisiasi menyusui dini dalam satu jam pertama kehidupan, bayi hanya menerima ASI tanpa tambahan makanan dan minuman, termasuk air, menyusui sesuai permintaan atau sesering yang diinginkan bayi dan tidak menggunakan botol atau dot (WHO, 2018).

Kementrian kesehatan menargetkan peningkatan target pemberian ASI eksklusif hingga $80 \%$. Namun pemberian ASI eksklusif di Indonesia pada kenyataannya masih rendah hanya $74,5 \%$ (Balitbangkes, 2019). Data profil kesehatan Indonesia, cakupan bayi mendapat ASI eksklusif tahun 2018 sebesar 68,74\% (Kemenkes, 2019).

Berdasarkan Data Profil Kesehatan Indonesia pemberian ASI Eksklusif pada bayi usia 06 bulan di Indonesia sebesar 55,7\%, dari standar yang diharapkan yaitu 80\%. Dengan presentasi pemberian ASI tertinggi berada di wilayah Nusa Tenggara Barat sebesar 86,9\% dan terendah di Provinsi Sulawesi Utara sebesar 26,3\%, sementara provinsi Sulawesi Tenggara angka cakupan ASI Ekslusif sebesar 54,1\% (Kemenkes RI, 2015). Persentase anak berumur dibawah 6 bulan yang mendapat ASI eksklusif meningkat dalam lima tahun terakhir, dari $42 \%$ pada Survei Demografi dan Kesehatan (SDKI) 2012 menjadi 52\% pada SDKI 2017. Namun persentase anak yang tidak mendapat ASI naik 8 persen dari SDKI 2012 menjadi 12\% pada SDKI 2017. Hampir $60 \%$ anak berumur dibawah 6 bulan mendapatkan ASI predominan (menerima ASI, air atau cairan selain ASI) dan 37\% anak dibawah 2 tahun menggunakan botol dot (SDKI, 2017).

Berdasarkan Profil Anak Indonesia (2018) provinsi dengan persentase tertinggi bayi yang diberi ASI eksklusif adalah Jawa Tengah sebesar 68,18\% sedangkan provinsi dengan persentase terendah bayi diberi ASI eksklusif adalah Gorontalo sebesar 24,96\%.Berdasarkan Profil Kesehatan Sumatera Utara (2017) cakupan persentase bayi yang diberi ASI eksklusif tahun 2016 terjadi penurunan yang tajam dibanding tahun 2015 dan tidak mencapai target nasional yaitu lebih kurang 40\% sebesar 28,5\% Kabupaten/Kota dengan pencapaian lebih kurang 40\% untuk Kabupaten yaitu Labuhanbatu Utara 4.069 bayi (97,90\%), Samosir 659 bayi (94,8\%), Humbang Hasundutan 1.796 bayi (84,0\%), Simalungun 5.411 bayi (60,6\%), Dairi 1.576 bayi $(55,7 \%)$, PakPak bharat 261 bayi (50,5\%), Deli Serdang 10.355 bayi (47,1\%), Asahan 3.317 bayi $(43,6 \%)$, Labuhan Batu 2.256 bayi (40,9\%) dan untuk Kota yaitu Gunung Sitoli 1.159 bayi $(84,5 \%)$, Sibolga 360 bayi (46,7\%). Sedangkan daerah dengan pencapaian $<10 \%$ yaitu Kota Medan 1.589 bayi (6,7\%) dan Tebing Tinggi 119 bayi (7,4\%).

Inisisasi Menyusui Dini (IMD) adalah meletakkan bayi secara tengkurap didada atau perut ibu sehingga kulit bayi melekat pada kulit ibu (Kemenkes, 2017). Tahap pertama IMD biasanya ia hanya akan diam selama 20-30 menit dan ternyata hal ini terjadi karena bayi sedang menetralisir keadaan setelah trauma. Menyusui sejak dini mempunyai dampak positif bagi ibu maupun bayinya. Bagi bayi, mempunyai peran penting yang fundamental pada kelangsungan hidup bayi (Yenie \& Mugiati, 2015).

Menurut Widuri (2013), ada beberapa upaya bagi ibu agar berhasil menyusui dengan baik dan lancar sejak proses menyusui, yaitu salah satunya dengan menyusui sesegera mungkin setelah bayi lahir yaitu diawali dengan IMD dan kontak kulit antara ibu dan bayi. Kontak langsung 
sangat dibutuhkan untuk menciptakan kepuasan bagi ibu dan juga bayi. Bayi merasa aman dan puas karena mendapatkan kehangatan dari dekapan ibunya. Ibu yang merasa rileks dan nyama maka pengeluaran ASI akan berlangsung baik. Refleks hisapan bayi pada puting ibu akan merangsang produksi ASI. Semakin awal dan semakin sering bayi menyusu, payudara akan memproduksi ASI lebih banyak. Adapun tujuan penelitian ini adalah Untuk mengetahui apakah ada hubungan inisiasi menyusui dini (IMD) dengan kelancaran produksi asi pada ibu post partum di Posyandu Desa Bangun Sari Baru Tanjung Morawa Tahun 2021.

\section{METODE PENELITIAN}

Jenis penelitian ini descriptive correlation, Dengan desain cross sectional, Penelitian ini di laksanakan di Posyandu Desa Bangun Sari Baru Tanjung Morawa, dengan populasi ibu post partum yang memiliki bayi $0-6$ bulan yang melakukan IMD dan tidak melakukan IMD di Posyandu Desa Bangun Sari Baru Tanjung Morawa yaitu sebanyak 31 orang. Adapun Teknik pengambilan sampel menggunakan teknik Total Sampling. Instrumen yang digunakan adalah lembar kuesioner dengan analisis data pada penelitian ini berupa univariat dan bivariat dengan menggunakan uji chi-square.

\section{HASIL}

Karakteristik responden yang diteliti dalam penelitian ini meliputi: Umur/Usia, pekerjaan, Pendidikan dan jumlah anak dapat dilihat pada table 1.

Tabel 1. Karakteristik Ibu Hamil di Posyandu Desa Bangun Sari Baru

\begin{tabular}{|c|c|c|c|}
\hline \multicolumn{4}{|c|}{ Tanjung Morawa Tahun 2021} \\
\hline No & Karakteristik & Frekuensi (f) & Persentase (\%) \\
\hline \multirow[t]{7}{*}{1} & Umur/Usia & & \\
\hline & $<20$ Tahun & 3 & 9,7 \\
\hline & 20-25 Tahun & 12 & 38,7 \\
\hline & 26-30 Tahun & 10 & 32,3 \\
\hline & 31-35 Tahun & 5 & 16,1 \\
\hline & $>35$ Tahun & 1 & 3,2 \\
\hline & Jumlah & 31 & 100,0 \\
\hline \multirow[t]{5}{*}{2} & Pendidikan & & \\
\hline & SMP & 8 & 25,8 \\
\hline & SMA & 21 & 67,7 \\
\hline & Diploma/ Perguruan Tinggi & 2 & 6,5 \\
\hline & Jumlah & 31 & 100,0 \\
\hline \multirow[t]{6}{*}{3} & Pekerjaan & & \\
\hline & Wiraswasta & 3 & 9,7 \\
\hline & Ibu Rumah Tangga & 16 & 51,6 \\
\hline & Karyawan Swasta & 7 & 22,6 \\
\hline & PNS & 5 & 16,1 \\
\hline & Jumlah & 31 & 100,0 \\
\hline \multirow[t]{6}{*}{4} & Jumlah Anak & & \\
\hline & 1 & 8 & 25,8 \\
\hline & 2 & 6 & 19,3 \\
\hline & 3 & 10 & 32,3 \\
\hline & $>3$ & 7 & 22,6 \\
\hline & Jumlah & 31 & 100,0 \\
\hline
\end{tabular}

Berdasarkan tabel 1 dari 31 orang responden yang diteliti dapat dilihat bahwa umur responden mayoritas adalah umur 20-25 Tahun sebanyak 12 orang $(38,7 \%)$, pendidikan responden mayoritas adalah SMA sebanyak 21 orang (67,7\%), Aktifitas ibu mayoritas adalah Ibu 


\section{Tahun 2022 \\ Hal. $37-43$ \\ E-ISSN $2774-4671$}

Rumah Tangga sebanyak 16 orang $(51,6 \%)$ dan jumlah anak mayoritas memiliki anak ketiga sebanyak 10 orang $(32,3 \%)$.

Tabel 2. Inisiasi Menyusui Dini (MD) Ibu Post Partum di Posyandu Desa Bangun Sari Baru Tanjung Morawa Tahun 2021

\begin{tabular}{clcc}
\hline No & Inisiasi Menyusui Dini (IMD) & Frekuensi (f) & \% \\
\hline 1 & Ya & 15 & 48,4 \\
2 & Tidak & 16 & 51,6 \\
\hline & Jumlah & $\mathbf{3 1}$ & $\mathbf{1 0 0}$ \\
\hline
\end{tabular}

Berdasarkan table 2. diatas dapat dilihat bahwa Inisiasi Menyusui Dini (MD) Ibu Post Partum di Posyandu Desa Bangun Sari Baru Tanjung Morawa mayoritas tidak melakukan inisiasi menyusui dini sebanyak 16 orang $(51,6)$ dan minoritas melakukan inisiasi menyusui dini sebanyak 15 orang $(48,4 \%)$.

Tabel 3. Kelancaran Produksi ASI Ibu Post Partum di Posyandu Desa Bangun Sari Baru Tanjung Morawa Tahun 2021

\begin{tabular}{clcc}
\hline No & $\begin{array}{c}\text { Kelancaran Produksi ASI Ibu } \\
\text { Post Partum }\end{array}$ & Frekuensi (f) & \% \\
\hline 1 & Lancar & 12 & 38,7 \\
2 & Tidak Lancar & 19 & 61,3 \\
\hline & Jumlah & $\mathbf{3 1}$ & $\mathbf{1 0 0}$ \\
\hline
\end{tabular}

Berdasarkan table 3. diatas dapat dilihat Kelancaran Produksi ASI Ibu Post Partum di Posyandu Desa Bangun Sari Baru Tanjung Morawa Tahun 2021 mayoritas kategori tidak lancar sebanyak 19 orang $(61,3 \%)$ dan dan minoritas adalah kategori lancar sebanyak 12 orang $(38,7 \%)$.

Tabel 4. Hubungan Inisiasi Menyusui Dini (IMD) dengan Kelancaran Produksi ASI Ibu Post Partum di Posyandu Desa Bangun Sari Baru Tanjung Morawa Tahun 2021

\begin{tabular}{|c|c|c|c|c|c|c|c|c|}
\hline \multirow[t]{3}{*}{ No } & \multirow[t]{3}{*}{ Variabel } & \multicolumn{4}{|c|}{ Kelancaran Produksi ASI } & \multirow{2}{*}{\multicolumn{2}{|c|}{ Total }} & \multirow{3}{*}{$\begin{array}{c}\text { Nilai p } \\
\text { Value }\end{array}$} \\
\hline & & \multicolumn{2}{|c|}{ Lancar } & \multicolumn{2}{|c|}{ Tidak Lancar } & & & \\
\hline & & $f$ & $\%$ & $f$ & $\%$ & $f$ & $\%$ & \\
\hline \multicolumn{9}{|c|}{ Inisiasi Menyusui Dini (IMD) } \\
\hline 1. & $\mathrm{Ya}$ & 9 & 75,0 & 6 & 31,6 & 15 & 100 & \multirow{3}{*}{0,018} \\
\hline 2. & Tidak & 3 & 25,0 & 13 & 68,4 & 16 & 100 & \\
\hline & Total & 12 & 100 & 19 & 100 & 31 & 100 & \\
\hline
\end{tabular}

Berdasarkan table 4. diatas dapat dilihat bahwa ibu post partum yang tidak melakukan inisiasi menyusui dini mengalami tidaklancaran produksi asi sebanyak 13 orang $(68,4 \%)$ dan ibu post partum yang tidak melakukan inisiasi menyusui dini dan mengalami kelancaran produksi asi sebanyak 3 orang $(25,0 \%)$. Kemudian berdasarkan hasil uji chisquare didapatkan bahwa nilai $p$ value sebesar $0,018<\alpha=0,05$ Sehingga dapat disimpulkan terdapat Hubungan Inisiasi Menyusui Dini (IMD) dengan Kelancaran Produksi ASI Ibu Post Partum di Posyandu Desa Bangun Sari Baru Tanjung Morawa Tahun 2021.

\section{PEMBAHASAN}

Berdasarkan hasil penelitian didapatkan bahwa Inisiasi Menyusui Dini (IMD) ibu post partum di Posyandu Desa Bangun Sari Baru Tanjung Morawa mayoritas tidak melakukan imd sebanyak 16 responden yaitu sebesar 51,6\%.

Inisiasi menyusui dini adalah proses membiarkan bayi dnegan nalurinya sendiri dapat menyusu segera dalam satu jam pertama setelah lahir, bersamaan dengan kontak kulit antara bayi dengan kulit ibu bayi dibiarkan setidaknya selama satu jam didada ibu, sampai dia menyusu sendiri (Depkes, 2014). Inisiasi Menyusui Dini (IMD) dalam penelitian ini adalah Inisiasi 


\section{JURNAL ILMIAH KEBIDANAN Tahun 2022 \\ E-ISSN $2774-4671$}

Menyusui Dini (IMD) ibu post partum di Posyandu Desa Bangun Sari Baru Tanjung Morawa Tahun 2021.

Inisiasi menyusui dini merupakan evidence based bayi baru lahir untuk satu jam pertama, adapun evidance based yang baru telah diperbarui oleh menurut WHO dan UNICEF tentang asuhan bayi baru lahir untuk satu jam pertama menyatakan bahwa bayi harus mendapatkan kontak kulit dnegan kulit dengan ibunya segera setelah lahir paling sedikit satu jam, bayi harus dibiarkan untuk melakukan inisiasi menyusui dini serta memberi bantuan jika diperlukan, dan menunda prosedur lainnya yang harus dlakukan kepada bayi baru lahir hingga inisiasi menyusui dini selesai dilakukan

Menurut asumsi peneliti masih tingginya angka inisiasi menyusui dini karena ketidakpercayaan masyarakat khususnya ibu hamil dengan kandungan yang terdapat dalam ASI dan masih tingginya angka dimana masyarakat masih percaya bahwa susu formula dapat membuat berat badan bayi lebih proporsional (gemuk). Kemudian ada beberapa hal yang menghambat ibu post partum untuk melakukan imd diantaranya faktor pekerjaan sehingga tidak dapat bersama bayinya selama 24 jam dan menggantikan tugas ibu sebagai pemberi makanan utama bagi bayi khususnya bayi usia 0-6 bulan dengan susu formula. Padahal pentingnya gizi yang ada didalam ASI ibu sangat mempengaruhi tumbuh kembang si bayi

Berdasarkan hasil penelitian dari 31 responden menunjukkan 19 responden $(59,4 \%)$ kelancaran produksi asinya dalam kategori tidak lancar.

Beberapa kriteria menurut Maritalia (2014), untuk mengetahui produksi ASI terdapat beberapa kriteria yang dipakai sebagai patokan untuk mengetahui jumlah ASI lancar atau tidak: ASI yang banyak dapat merembes keluar dari puting, sebelum disusukan payudara terasa tegang, payudara ibu terasa lembut dan kosong setiap kali menyusui, bayi paling sedikit menyusu 8-10 kali dalam 24 jam,ibu dapat merasakan rasa geli karena aliran ASI setiap kali mulai menyusui. Payudara terasa lebih lembek, yang menandakan ASI telah habis, ibu dapat mendengar suara menelan yang pelan ketika bayi menelan ASI, berat badan bayi naik dengan memuaskan sesuai umur, ASI cukup diketahui ketika setelah menyusui bayi akan tertidur selama 3-4 jam, bayi sekurang-kurangnya buang air kecil 6-8 kali dalam sehari, bayi mengeluarkan urin berwarna kuning pucat dan bayi BAB satu kali dalam 24 jam, kotoran bayi berwarna kuning

Sedangkan menurut Alisa (2016) untuk mengetahui jumlah ASI lancar atau tidaknya dapat terlihat pada penambahanberat badan bayi yang baik. Dalam keadaan normal usia 0-5 hari biasanya berat badan bayi akan menurun, setelah usia 10 hari berat badan bayi akan kembali normal.

Menurut asumsi peneliti, terjadinya ketidaklancaran produksi ASI disebabkan beberapa faktor, diantaranya adalah ibu post partum tidak sesering mungkin memberikan atau menyusui bayinya sehingga mempengaruhi kelancaran pengeluaran ASI. Kemudian, dari hasil yang didapatkan dilapangan, responden mengatakan tidak melakukan pola makannya dengan baik atau terkadang lupa untuk mengkonsumsi makanan karena sibuk akan pekerjaannya atau terlalu banyak pekerjaan.

Berdasarkan hasil penelitian didapatkan bahwa ibu post partum yang tidak melakukan inisiasi menyusui dini mengalami tidaklancaran produksi asi sebanyak 13 orang $(68,4 \%)$ dan ibu post partum yang tidak melakukan inisiasi menyusui dini dan mengalami kelancaran produksi asi sebanyak 3 orang $(25,0 \%)$. Kemudian berdasarkan hasil uji chisquare didapatkan bahwa nilai $p$ value sebesar $0,018<\alpha=0,05$ Sehingga dapat disimpulkan terdapat Hubungan Inisiasi Menyusui Dini (IMD) dengan Kelancaran Produksi ASI Ibu Post Partum di Posyandu Desa Bangun Sari Baru Tanjung Morawa Tahun 2021.

Sejalan dengan penelitian Nurbaiti (2020) yang menyebutkan bahwa terdapat hubungan inisiasi menyusui dini (imd) dengan kelancaran produksi asi pada ibu post partum dengann hasil uji chi square didapatkan $p$ value 0,006 . Hal tersebut dikarenakan masih rendahnya pelaksanaan program IMD dan kurangnya kesadaran dari ibu sendiri.

Begitu juga dengan penelitian Setyowati (2018) yang menyebutkan bahwa terdapat hubungan inisisasi menyusui dini dengan produksi asi selama 6 bulan pertama. Dimana 
berdasarkan 31 responden didapatkan 25 responden (80,7\%) melakukan IMD secara dini. Diliha dari hasil uji statistik pada penelitian ini terdapat hubungan yang signifikan antara IMD secara dini dnegan keberhasilan pemberian ASI secara eksklusif yaikni 6 bulan pertama kehidupan bayi. Ibu nifas yang melakukan inisiasi menyusui dini dalam kurun waktu dari satu jam akan membantu kelancaran pengeluaran ASI lebih cepat.

Menurut asumsi peneliti bahwa ibu post partum yang melakukan inisiasi menyusui dini (IMD) maka akan semakin lancar produksi asi yang dihasilkan oleh ibu post partum dan sebaliknya jika tidak melakukan inisisasi menyusui dini maka akan berpengaruh terhadap terhambatnya proses pengeluaran asi atau produksi asi.

\section{KESIMPULAN}

Berdasarkan penelitian yang dilakukan di Posyandu Desa Bangun Sari Baru Tanjung Morawa Tahun 2021 didapatkan Inisisasi menyusui dini di Posyandu Desa Bangun Sari Baru Tanjung Morawa mayoritas tidak melakukan inisiasi menyusui dini (IMD). Kelancaran produksi asi di Posyandu Desa Bangun Sari Baru Tanjung Morawa mayoritas kategori tidak lancar.Terdapat Hubungan Inisisasi Menyusui Dini (IMD) dengan kelancaran Produksi ASI Pada Ibu Post Partum di Posyandu Desa Bangun Sari Baru Tanjung Morawa Tahun 2021.

\section{REFERENSI}

Balitbagkes, 2019. Laporan Nasional Riskesdas 2018. https://doi.org/ISBN978-602-373-116-3. Bayu, 2014. Pintar ASI dan Menyusui. Jakarta : Panda Media.

Depkes, 2017. Profil Kesehatan Indonesia Tahun 2017. Retrieved from Profil Kesehatan Indonesia Tahun 2017. Website : www.depkes.go.id.

Depkes RI, 2014. Profil Kesehatan Indonesia. Departemen Kesehatan Republik Indonesia. Jakarta.

Dewi \& Sunarsih, 2012. Asuhan Kebidanan Pada Ibu Nifas. Jakarta : Salemba Medika.

Djanah, 2017. Akupresur Terhadap Produksi ASI Pada Ibu Post Partum. Skripsi. Jurusan kebidanan Poltekkes Yogyakarta. Yogyakarta.

Haryono, R, 2014. Manfaat ASI Eksklusif Untuk Buah Hati Anda. Gosyen Publishing. Edisi 1. Hal: $17-30$.

Kemenkes RI, 2017. Profil Kesehatan Indonesia Tahun 2016. Jakarta : Kementrian Kesehatan Republik Indonesia.

2015. Data dan Informasi Profil Kesehatan Indonesia Cakupan Bayi dengan ASI Eksklusif. Retrieved from Data dan Informasi Profil Kesehatan Indonesia Cakupan Bayi dengan ASI Ekslusif. Website : www.depkes.go.id.

, 2019. Data dan Informasi Profil Kesehatan Indonesia Cakupan Bayi dengan ASI Eksklusif. Retrieved from Data dan Informasi Profil Kesehatan Indonesia Cakupan Bayi dengan ASI Ekslusif. Website : www.depkes.go.id.

, 2017. Profil Kesehatan Sumatera Utara Tahun 2016. Diakses dari https://www.depkes.go.id

Kementrian Perempuan dan Perlindungan Anak, 2018. Profil Anak Indonesia 2017. Diakses dari http://www.kemenppa.go.id

Khasanah, 2011. ASI atau Susu Formula Ya. Yogyakarta : FlashBooks.

Lestari , 2014. Beberapa Faktor yang Mempengaruhi Kegagalan IMD (Tesis). Semarang : Undip. , 2018. Peningkatan Pengeluaran ASI dengan Kombinasi Pijat Oksitosin dan Teknik Marmet Pada Ibu Post Partum. Jurnal Kebidanan.

Marni, 2015. Asuhan Neonatus, Bayi, balita, dan Anak Prasekolah. Yogyakarta : Pustaka Pelajar.

Martalia, 2012. Asuhan Kebidanan Nifas dan Menyusui . editor Suyono Riyadi. Yogyakarta : Pustaka Belajar.

Maryunani, 2015. Inisiasi Menyusui Dini, ASI Eksklusif dan Manajemen Laktasi. 


\section{JURNAL ILMIAH KEBIDANAN

Monika, 2014. Buku Pintar ASI dan Menyusui. Mizan publika : Jakarta Selatan. Nugroho, 2014. Obgyn : Obstetrik dan Ginekologi. Yogyakarta : Nuha Medika. Medika.

, T, 2011. Buku Ajar Obstetrik Untuk mahasiswa Kebidanan. Yogyakarta : Nuha

Nurjannah, 2013. Asuhan Kebidanan Post Partum Dilengkapi dengan Asuhan Kebidanan Post Sectio Caesarea. Bandung : PT Refrika Aditama.

Pollard, 2016. ASI Asuhan Berbasis Bukti. Jakarta : Penerbit Buku Kedokteran EGC.

Puput, 2019. Angka Pemberian ASI Eksklusif di Indonesia Masih Rendah. Retrieved from AngkaPemberian ASI Eksklusif di Indonesia Masih Rendah. Website : http://m.cnnindonesia.com.

Roesli, 2008. IMD Plus ASI Eksklusif. Jakarta : Pustaka Bunda.

Setiadi, 2013. Konsep dan Praktek Penulisan Riset Keperawatan (Ed.2). Yogyakarta : Graha Ilmu.

Sondakh, 2013. Asuhan Kebidanan Persalinan dan Bayi Baru lahir. Erlangga.

Sukrita, 2017. ASI dan Menyusui. Jakarta : Pustaka Bunda.

Sulistyawati, 2015. Asuhan Kebidanan Pada Masa Kehamilan. Jakarta : Salemba Medika.

World Health Organization (WHO), 2018. Exclusive Breastfeeding. (Online). http://www.who.int/nutrition/topic/exclusive breastfeeding/en/.

Widuri, 2013. Cara Mengolah ASI eksklusif Bagi Ibu Bekerja. Yogyakarta : Gosyen Publishing.

Winkjosaastro, 2012. Ilmu Kebidanan. Jakarta : Yayasan Bina Pustaka Sarwono Prawiroharjo.

Wulandari \& Handayani, 2011. Asuhan Kebidanan Ibu Masa Nifas. Yogyakarta : Gosyen Publishing.

Yahya, 2007. Cairan Ajaib Air Susu Ibu. Jakarta : Medika.

Yenie \& Mugiati, 2015. Hubungan Inisiasi Menyusui Dini (IMD) dengan Waktu Pengeluaran Kolostrum pada Ibu Bersalin di BPM Wilayah Kerja Puskesmas Kalirejo Kabupaten Pesawaran tahun 2015. Jurnal Keperawatan. 